Article

\title{
The Collective Contribution of Atmospheric and Oceanic Components to ENSO Asymmetry
}

\author{
Yanli Tang ${ }^{1,2}$, Lijuan Li ${ }^{1, *}$, Bin Wang ${ }^{1,3}$, Pengfei Lin ${ }^{1}$, Wenjie Dong ${ }^{4}$ and Kun Xia ${ }^{1}$ \\ 1 State Key Laboratory of Numerical Modeling for Atmospheric Sciences and Geophysical Fluid Dynamics \\ (LASG), Institute of Atmospheric Physics, Chinese Academy of Sciences, Beijing 100029, China \\ 2 State Key Laboratory of Severe Weather, Chinese Academy of Meteorological Sciences, Beijing 100081, China \\ 3 Ministry of Education Key Laboratory for Earth System Modeling, Center of Earth System Science (CESS), \\ Tsinghua University, Beijing 100084, China \\ 4 School of Atmospheric Sciences, Sun Yat-sen University, Zhuhai 519082, China \\ * Correspondence: ljli@mail.iap.ac.cn; Tel.: +86-10-8299-529
}

Received: 21 July 2019; Accepted: 13 August 2019; Published: 15 August 2019

check for updates

\begin{abstract}
Four cross-coupled models were used to investigate the relative contributions of atmospheric and oceanic components to the asymmetry of the El Niño-Southern Oscillation (ENSO). Strong El Niño and La Niña events related to the negative heat flux feedbacks were found to be determined mainly by the atmospheric component, and the stronger sea surface temperature (SST) anomalies in the warm phase did not lead to an increased SST asymmetry. The skewness of the four models could be affected by both atmospheric and oceanic components; the atmospheric component determines the strength of positive and negative SST anomalies, and the oceanic component affects the strength of the negative SST anomalies in the cold phase under the same atmospheric component group. The Bjerknes stability index (BJ index) of warm and cold phases contributed to the El Niño-La Niña SSTA asymmetries in observation, but the BJ index did not necessarily explain the El Niño-La Niña SSTA asymmetries in climate model simulations. The SST asymmetries in these four models were closely associated with convective precipitation and wind stress asymmetries, which are also determined by both the atmospheric and oceanic components.
\end{abstract}

Keywords: ENSO asymmetry; cross-coupled models; heat flux; convective precipitation; zonal wind stress

\section{Introduction}

The El Niño-Southern Oscillation (ENSO) is characterized as a sea surface temperature anomaly in the central-eastern equatorial Pacific that occurs every 2-7 years with considerable irregularity in amplitude, duration, and temporal evolution [1]. Furthermore, the conditions that develop during warm and cold phases of ENSO are not mirror images of each other. Statistically, the amplitude of the El Niño-related anomaly is stronger than that of the La Niña anomaly, which, on average, causes a positive residual effect. As a prominent feature of ENSO, this asymmetry is not only associated with the more frequent extreme El Niño events than extreme La Niña events, but the residual effect can also influence the decadal variation of the mean state in the tropics via nonlinear rectification [2,3]. Understanding the causes and the consequences of ENSO asymmetry may help to improve our understanding of the interannual/decadal variability in the tropics and also help us to better predict ENSO in the future.

The characteristics and the causes of asymmetry in observations and climate models have been extensively investigated. Dommengent et al. [4] analyzed the ENSO pattern using the observation dataset and showed that a strong El Niño has empirical orthogonal function (EOF)-1 and EOF-2 patterns with the same sign superimposed upon it, whereas a strong La Niña has a negative EOF-1 
pattern and a positive EOF-2 pattern superimposed upon it. The nonlinear composite of principal component (PC)-1 and PC-2 manifests as the asymmetry of extreme ENSO events. The nonlinearity of oceanic behavior can lead to the asymmetric nature. An et al. [5] found that, during the development of strong El Niño, the enhancement of the vertical advection induces the anomalous warm water in the subsurface to upwell to the surface layer, which results in a nonlinear acceleration of surface warming, whereas during the transition to La Niña, there is an anomalous downwelling caused by the westerly wind anomalies, which results in the slowdown of the surface cooling. Su et al. [6] calculated the mixed-layer temperature tendency of the Simple Ocean Data Assimilation (SODA) reanalysis and indicated that the linear advection term leads to the symmetry of warm and cold phases, whereas the nonlinear advection tends to enhance El Niño but weaken La Niña and thus is responsible for the amplitude asymmetry. Alternatively, the asymmetric nature may originate from nonlinear atmospheric processes. Tropical convection is not linear for the opposite sea surface temperature (SST) anomalies [7], and an asymmetric response in the precipitation leads to an asymmetric response in location, strength, or pattern of the zonal wind stress, which in turn results in the sea surface temperature (SST) asymmetry [1,8-11]. Moreover, Ham [12] showed that the change in the atmospheric feedbacks (i.e., the SST for maximum precipitation sensitivity) caused by the background SST can affect the asymmetry of ENSO under global warming.

The results of modeling and observations/reanalysis described above demonstrated that both atmospheric and oceanic processes can cause the ENSO asymmetry. However, the relative contributions of atmospheric and oceanic components to ENSO asymmetry could not be determined when using a single model or independent multi-models. Hence, this study examined their relative contributions using four "cross-coupled" models: Community Earth System Model CESM1.2.0 (known to simulate a strong ENSO amplitude), the Flexible Global Ocean-Atmosphere-Land System Model (grid-point Version 2; FGOALS-g2), CESM-g2, and FGOALS-c4 [13,14].

\section{Models and Datasets}

\subsection{Model Description and Experiment Design}

The first parent coupled model used here was the Community Earth System Model (CESM). The atmospheric component of CESM is Version 4 of the Community Atmosphere Model (CAM4) [15], in which the vertical coordinate is a hybrid sigma-pressure scheme with 30 layers, and the horizontal coordinate is a finite-volume grid with a resolution of $2^{\circ}$. The oceanic component is Version 2 of the Parallel Ocean Program (POP2) [16] with a $1^{\circ}$ displaced pole grid in horizon.

The other parent model used was the Flexible Global Ocean-Atmosphere-Land System Model (Grid-point Version 2; FGOALS-g2). The atmospheric component of this model was the Grid-point Atmospheric Model of IAP LASG Version 2 (GAMIL2), which uses a dynamical core including a finite difference scheme and a two-step shape-preserving advection scheme with a vertical sigma coordinate of 26 layers and a hybrid horizontal grid of $2.8^{\circ}[17,18]$. The oceanic component was the LASG IAP Climate System Ocean Model version 2 (LICOM2) [19], using a latitude-longitude grid of $1^{\circ}\left(0.5^{\circ}\right.$ meridional refined resolution in the tropics) in horizon [20].

The two atmospheric and the two oceanic components outlined above were cross-coupled as follows: GAMIL2 and POP2 were combined to CESM-g2 (the GAMIL2 nest into the CESM) [13,21], and CAM4 and LICOM2 were combined to FGOALS-c4 (the CAM4 nest into FGOALS-g2) [22]. That is, FGOALS-g2 and CESM-g2 shared the GAMIL2 atmospheric component, and CESM and FGOALS-c4 shared the CAM4 atmospheric component, whereas FGOALS-g2 and FGOALS-c4 shared the LICOM2 oceanic component, and CESM and FGOALS-c4 shared the POP2 component.

To prevent any impact on ENSO from changes caused by external forcing, the CESM, the CESM-g2, and the FGOALS-c4 models were integrated over 500 years under the external forcing in the pre-industrial (PI) scenario, and the PI-control simulation (years 1-500) of FGOALS-g2 was obtained from the CMIP5 website. As shown in our previous paper [14], the four simulations generated by the four models in 
the PI-control runs were all stable over the period 401-500 years. Therefore, the monthly simulations for this 100 year period generated by the four models were used in this study. In addition, it is worth noting that the couplers for the CESM-g2, the CESM, and the FGOALS-c4 were CPL7, and the coupler of FGOALS-g2 was CPL6. The flux calculations and the interpolation methods between CPL6 and CPL7 were similar, and a previous study [14] demonstrated that, although the couplers of CESM-g2 and FGOALS-g2 were distinct, the ENSO amplitude differences between them were slight-much less than the differences between different atmospheric components. Hence, in this study, the effects of the different couplers were also ignored.

\subsection{Validation Datasets and BJ Stability Index Analysis}

The following observations and reanalysis datasets were used to verify the model runs. The SST data were obtained from the merged products of HADISST1 (i.e., the Met. Office Hadley Centre sea ice and SST dataset (from 1870 onwards) and OI.v2 (i.e., the National Oceanic and Atmospheric Administration Optimum Interpolation SST Version 2 dataset; from November 1981 onwards)) [23]. We used the heat fluxes data from the 40 year European Centre for Medium-Range Weather Forecasts Re-Analysis (ERA-40) [24] and the precipitation dataset for the period 1984-2009 generated by the Global Precipitation Climatology Project (GPCP) [25]. The zonal wind stress data used were the SODA version 2.2.4 reanalysis for 1958-1999 [26,27].

The BJ index adopted in this paper followed that of Kim and Jin [28], which was modified based on Jin et al. [29]. The formulation is as follows:

$$
B J=\frac{R-\varepsilon}{2}
$$

and

$$
R=-\left(a_{1} \frac{<\Delta \bar{u}>_{E}}{L_{x}}+a_{2} \frac{<\Delta \bar{v}>_{E}}{L_{y}}\right)-\alpha_{s}+\mu_{a} \beta_{\mu}<-\frac{\partial \bar{T}}{\partial x}>_{E}+\mu_{a} \beta_{\omega}<-\frac{\partial \bar{T}}{\partial z}>_{E}+\mu_{a} \beta_{h}<\frac{H(\bar{\omega}) \bar{\omega}}{H_{1}}>a_{E}
$$

$\mathrm{R}$ represents the growth rate of the BJ index. In this paper, the difference in $\mathrm{R}$ between El Niño and La Niña events was required for the examination. The terms of the right hand of Equation (2) represent dynamic damping by mean advection (MA), thermodynamic damping (TD), zonal advective feedback (ZA), Ekman feedback (EK), and thermocline feedback (TH), respectively. The BJ index analysis was separately applied in the El Niño events and the La Niña events for the observations and the four coupled models.

\section{Results and Analysis}

\subsection{Asymmetry in the SST Fields}

Table 1 lists the skewness and the standard deviation of the monthly SST anomalies (SSTA) over the Niño-3 region based on the observations for the period 1900-1999 and from the four coupled models during four time slices from years 101-500. Generally, CESM showed the strongest skewness that was comparable with the observations in all four time slices, whereas the other three models all underestimated the asymmetry, and the value of FGOALS-g2 was uniformly negative. The value of the SST skewness changed frequently during different periods in all four models; in particular, the positive value turned negative in CESM-g2 and FGOALS-c4. The relative change in skewness over the different periods among the four models was far less than their biases and therefore did not affect the qualitative explanation (outlined above) of the underlying mechanism that drives ENSO asymmetry. Consequently, the following analysis of the four models in this study was based on the period covered by years 401-500. For the ENSO amplitude simulation (Table 1), the atmospheric component played the dominant role [14]. However, for ENSO skewness, the difference between CESM-g2 and FGOALS-g2 and between CESM and FGOALS-c4 (with the same atmospheric component) was still very large, 
indicating that, besides the atmospheric component, the oceanic component had an obvious influence. Moreover, a high ENSO variance did not necessarily mean large ENSO asymmetry, which conforms with the view of Zhang and Sun [10].

The histograms of the monthly area averaged SSTA over the Niño-3 region from the models (years 401-500) and the observations (1900-1999) are shown in Figure 1. In the observations, the SSTA distribution showed a longer tail on the right, i.e., the strong El Niño events were more frequent than the strong La Niña events, and the maximum positive anomaly reached $4 \mathrm{~K}$, whereas the negative anomaly was limited to only $-2.2 \mathrm{~K}$. Weak warm events appeared less frequently than weak cold events. In the simulations, the extreme warm and cold events occurred mainly in the CAM4-related simulations (CESM and FGOALS-c4), and the GAMIL2-related models (CESM-g2 and FGOALS-g2) did not show the long tail and generated only the weaker ENSO events. It seems that the strong events were determined by the atmospheric component, whereas the weak ENSO events were determined by both of atmospheric and oceanic components. In addition, grouped by the appearance of extreme events, the tail toward the warm phase and the cold phase also differed. In the GAMIL2-related models, the asymmetry of CESM-g2 was toward El Niño, and that of FGOALS-g2 was toward La Niña. In the CAM4-related models, this asymmetry toward the warm phase was apparent in CESM, whereas for FGOALS-c4, as there were proportions of both extreme cold events and extreme warm events, the asymmetry toward the warm phase was slight. The SSTA distributions were consistent with the skewness values (401-500) in Table 1.

(a) Observations
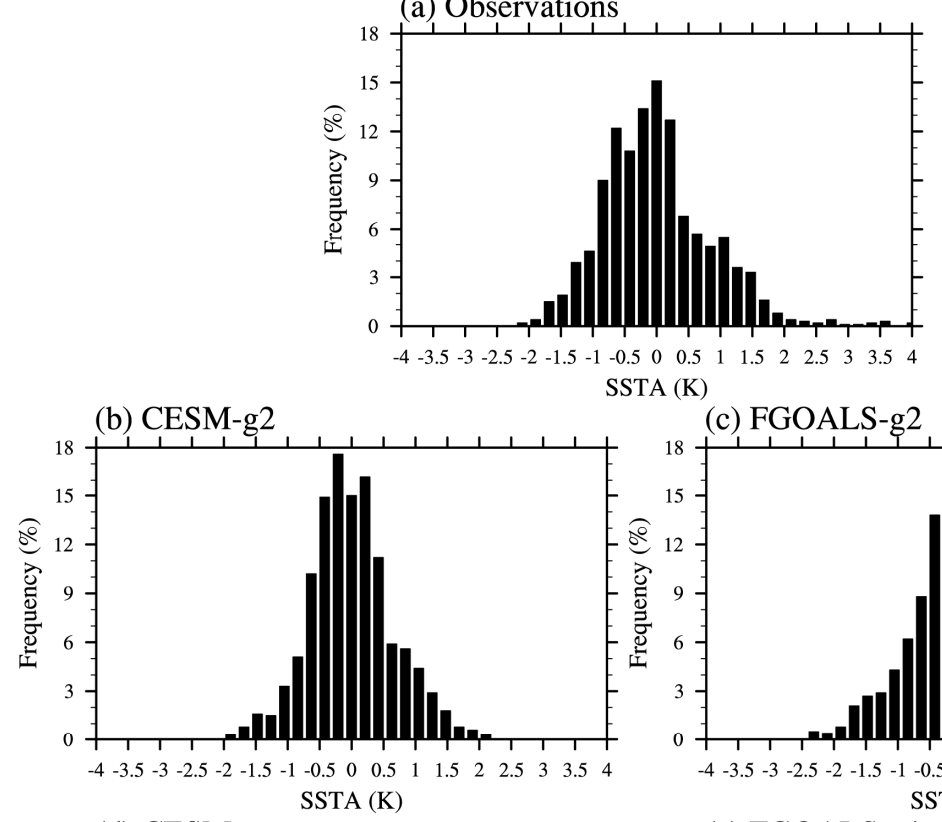

(c) FGOALS-g2
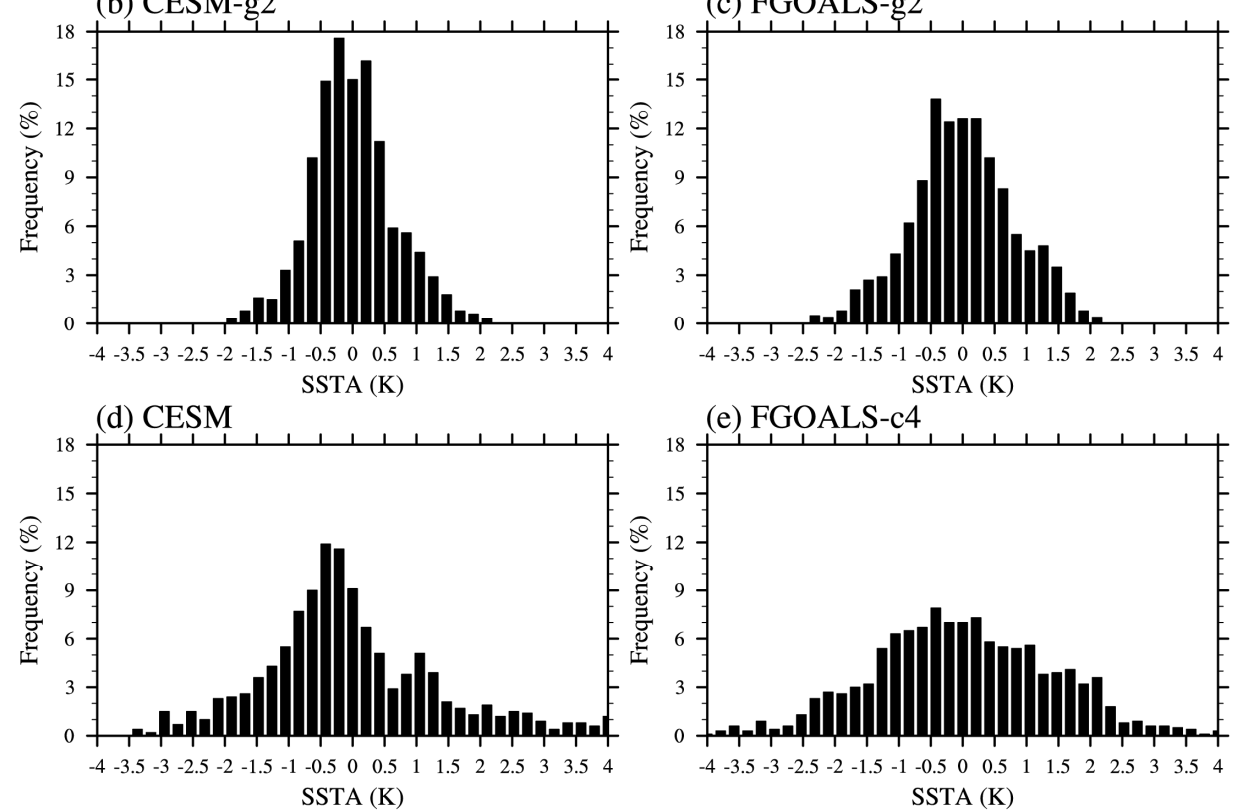

(e) FGOALS-c4

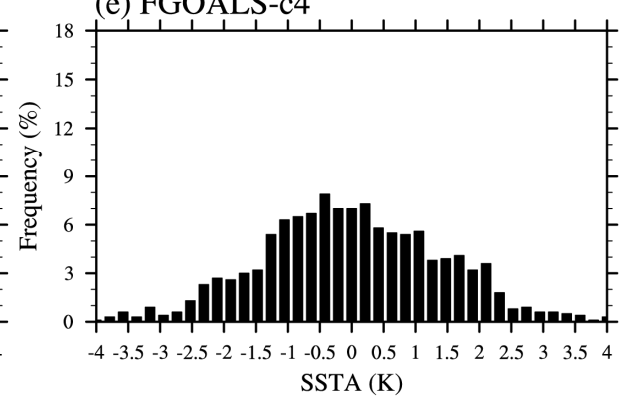

Figure 1. Distribution histograms of the monthly sea surface temperature (SST) anomalies averaged over Niño-3 $\left(5^{\circ} \mathrm{N}-5^{\circ} \mathrm{S}, 150^{\circ}-90^{\circ} \mathrm{W}\right)$ region from (a) the observations for years 1900-1999 and from the four models: (b) CESM-g2, (c) FGOALS-g2, (d) CESM, (e) FGOALS-c4 for years 401-500 in the pre-industrial (PI)-control runs. The width of the bin was $0.2 \mathrm{~K}$. 
Table 1. Skewness and standard deviations of monthly SST anomalies (SSTA) over the Niño-3 region for the Hadley Centre sea ice and SST (HADISST) observations over the period 1900-1999 and for the four parent models [Community Earth System Model (CESM)-g2, Flexible Global Ocean-Atmosphere-Land System Model (FGOALS)-g2, CESM, and FGOALS-c4) during years 401-500 from the PI-control run. The skewness of the four models during years 101-200, 201-300, and 301-400 is also listed. (The units of standard deviations: K).

\begin{tabular}{cccccc}
\hline & Standard Deviation & \multicolumn{4}{c}{ Skewness } \\
\hline Observations & $\mathbf{0 . 8 1}$ & \multicolumn{4}{c}{$\mathbf{0 . 6 0 3}$} \\
\hline Years & $401-500$ & $401-500$ & $301-400$ & $201-300$ & $101-200$ \\
\hline CESM-g2 & 0.63 & 0.103 & -0.27 & -0.11 & 0.20 \\
FGOALS-g2 & 0.77 & -0.246 & -0.18 & -0.22 & -0.07 \\
CESM & 1.37 & 0.625 & 0.60 & 0.52 & 0.40 \\
FGOALS-c4 & 1.37 & 0.016 & 0.35 & 0.41 & -0.19 \\
\hline
\end{tabular}

To further illustrate the details of the asymmetry, the composite of El Niño and La Niña events was calculated for the observations and the four coupled models. When the SST anomalies averaged in Niño-3 were greater (lower) than $0.5 \mathrm{~K}(-0.5 \mathrm{~K})$ for five consecutive months, we classified this as one El Niño (La Niña) event. The spatial pattern of the averaged composite SST anomalies for the warm and the cold events is shown in Figure 2. In the observations, the warm phase exhibited stronger SST anomalies than the cold events over the eastern Pacific and the South American coasts with a maximum value of about $1.5 \mathrm{~K}$. In the GAMIL2-related models, the positive SST anomalies during the warm phase were weaker and had a narrower meridional extension than in the observations, but the negative SST anomalies during the cold phase were similar to-or stronger than-those in the observations. In FGOALS-g2, the SST anomalies during the cold phase were stronger than during the warm phase, thus leading to a negative skewness value. In CESM-g2, the SST anomalies during the warm phase were moderately stronger than during the cold phase, and this resulted in the weak positive skewness. In the CAM4-related models, both SST anomalies of the warm and the cold composites were much stronger than in the observations. The positive SST anomalies in CESM were stronger than those in the cold phase, as in the observations, thus the simulated skewness was close to the observed value. The negative SST anomalies in FGOALS-c4 were comparable with those from the positive phase; thus, the positive residual was small, which indicated that stronger SST anomalies in the warm phase did not necessarily lead to an increase in SST asymmetry. This differs from the relationship described by Zhang and Sun (Figure 2) [11], who attributed the underestimation of the asymmetry in the climate models to the weaker biases of the warm phase. Moreover, we found that, in the same atmospheric component group, the POP2-related model (CESM-g2 and CESM) exhibited a weaker SST anomaly than the LICOM2-related model (FGOALS-g2 and FGOALS-c4) in the cold phase. Overall, the skewness could be affected by both the atmospheric and the oceanic components, i.e., the atmospheric component determined the strength of the SST anomalies, and the oceanic component then further affected the strength of the negative SST anomalies during the cold phase under the same atmospheric component group. 
(a) Warm phase (K)
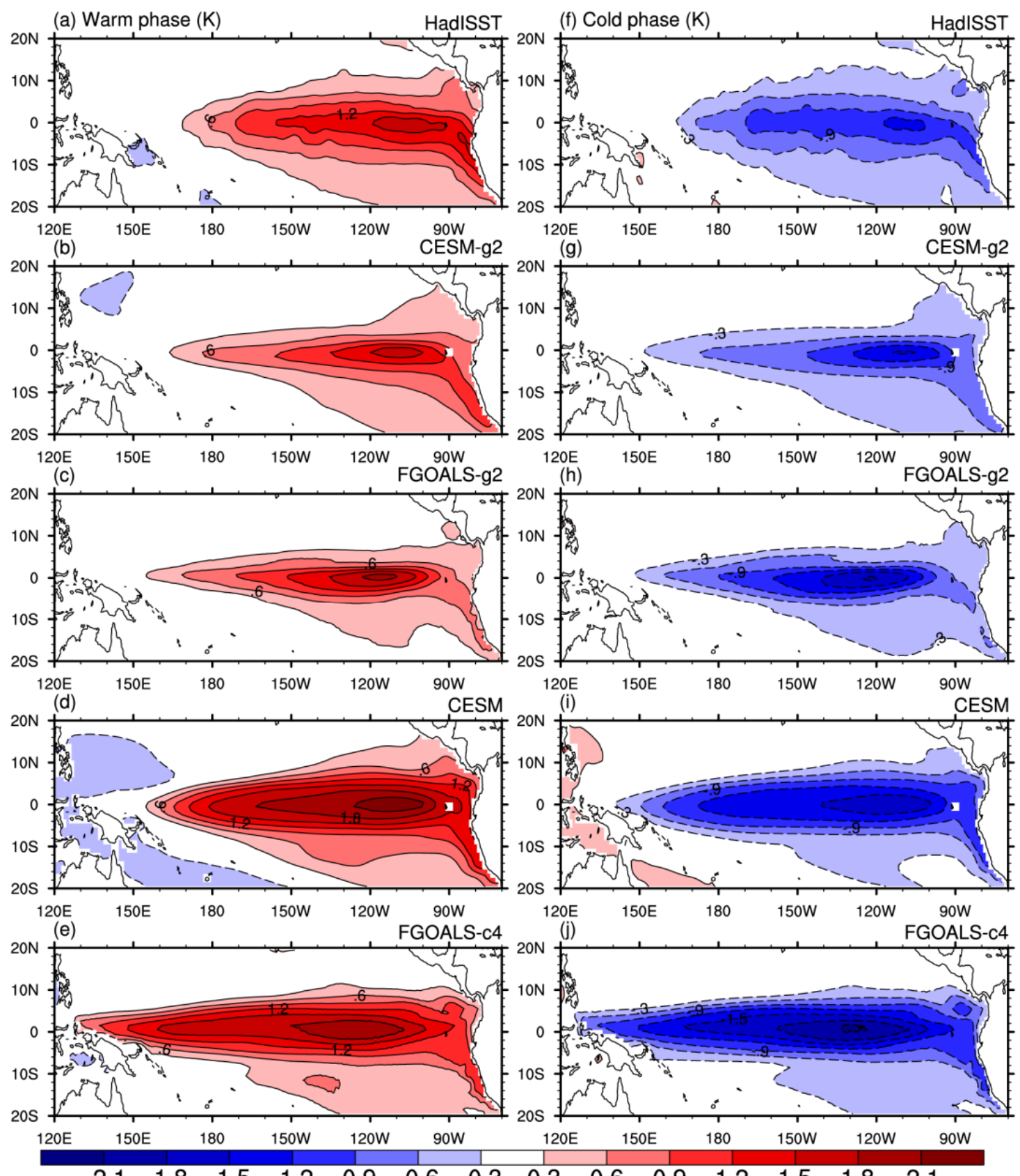

$\begin{array}{llllllllllllll}-2.1 & -1.8 & -1.5 & -1.2 & -0.9 & -0.6 & -0.3 & 0.3 & 0.6 & 0.9 & 1.2 & 1.5 & 1.8 & 2.1\end{array}$

Figure 2. Spatial pattern of averaged composite SST anomalies for El Niño (Left) and La Niña (right) events from the (a,f) observations and the four cross-coupled parent models: (b,g) CESM-g2, $(\mathbf{c}, \mathbf{h})$ FGOALS-g2, (d,i) CESM, (e,j) FGOALS-c4. The criterion for an El Niño (La Niña) event is that SST anomalies averaged in the Niño-3 area are greater (less) than $0.5 \mathrm{~K}(-0.5 \mathrm{~K})$ for five consecutive months. The period used for the composites was 100 years, i.e., 1900-1999 for the observations and 401-500 for the parent models.

\subsection{The Factors Affecting the Asymmetry of the SST Anomalies}

Previous studies demonstrated that ENSO amplitudes are positively correlated with the Bjerknes stability index (BJ index; Jin et al.) [28-30], which indicates the growth rate of ENSO. In order to investigate whether the BJ index contributed to the El Niño-La Niña SSTA asymmetries, the BJ index and the five contributed terms were separately applied in El Niño events and La Niña events for the observation and the four coupled models. As shown in Figure 3, in observation, the BJ index of an El Niño event $\left(-2.02\right.$ year $\left.^{-1}\right)$ was larger than that of a La Niña event $\left(-3.01\right.$ year $\left.^{-1}\right)$, which illustrated the 
stronger SST anomalies during the former compared to the latter (Figure 2a,f). Of the five contributed terms, the relative magnitudes of negative MA term and three positive ( $\mathrm{ZA}, \mathrm{TH}$, and $\mathrm{EK})$ terms in two phases all benefited the different $B J$ index. While the stronger damping TD feedback in the warm phase had an opposite contribution, the results were consistent with Im et al [31], which may have been associated with the nonlinear behavior of cloud and water vapor feedback. For example, it was found that the cloud-radiative feedback in the cold phase had weaker magnitude than the warm phase in observation [32,33]. For the four simulations, the BJ index of CESM-g2 and FGOALS-g2 in two phases reached an agreement with the skewness, while that of CESM and FGOALS-c4 was not self-consistent with the corresponding El Niño-La Niña asymmetry. CESM had an apparent positive skewness (0.625), while the BJ index values of the two phases were approximate. In contrast, the obvious different BJ index between two phases had a weak positive skewness (0.016). It was concluded that the BJ index did not necessarily explain the El Niño-La Niña SSTA asymmetries in climate model simulations. It was also found that, although the relative magnitudes of the BJ index between the two phases were different in the four simulations, the damping TD feedbacks during El Niño were all stronger than those during La Niña.

\section{BJ-Index}

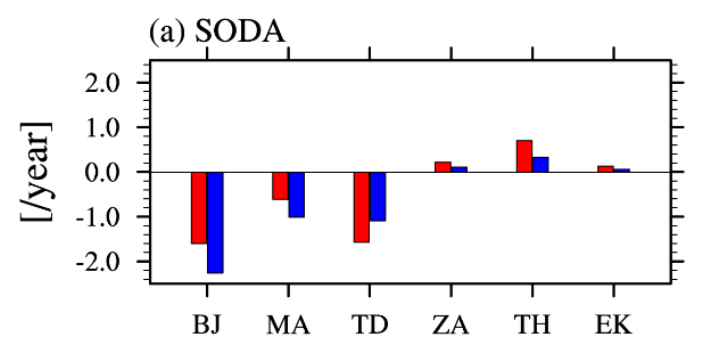

(b) CESM-g2

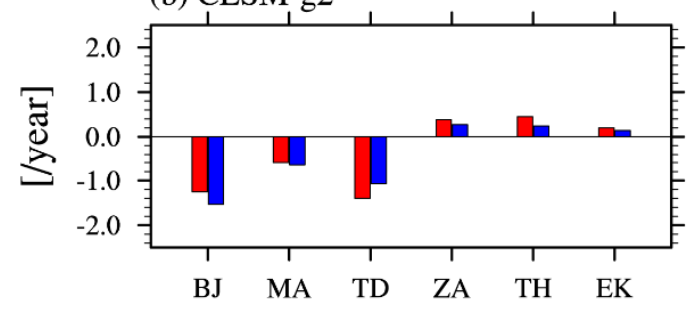

(d) CESM

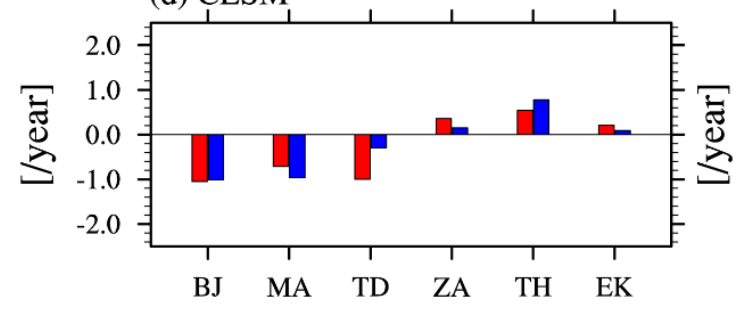

$\square$ El Nino (c) FGOALS-g2

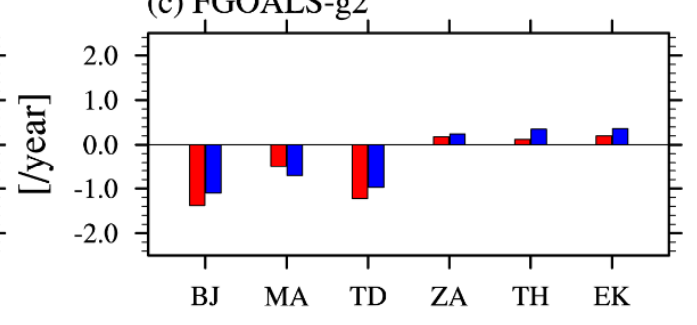

(e) FGOALS-c4

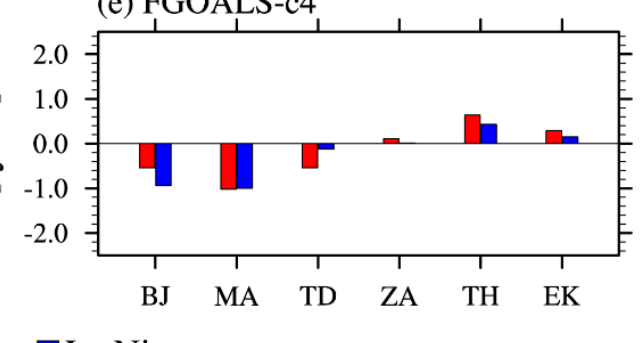

- La Nina

Figure 3. The Bjerknes stability (BJ) index and the five contributed terms in El Niño events and La Niña events for (a) the Simple Ocean Data Assimilation (SODA) 2.2.4 (years 1958-1999) and four coupled models: (b) CESM-g2, (c) FGOALS-g2, (d) CESM, (e) FGOALS-c4 (years 401-500 in the PI-control runs). 
To further investigate ENSO asymmetry, we analyzed the associated precipitation and zonal wind stress during the developing phase of El Niño [1,34]. Figure 4 shows the composite of the precipitation anomalies and the zonal wind stress anomalies during El Niño and La Niña events from the observations and the four coupled models. In the observations, the maximum positive precipitation anomalies during the warm phase were clearly evident between $175^{\circ} \mathrm{E}$ and $170^{\circ} \mathrm{W}$, whereas the precipitation anomalies during the cold phase shifted westwards, and the maximum strength was located between $160^{\circ} \mathrm{E}$ and $170^{\circ} \mathrm{E}$. Thus, the observations showed an obvious asymmetry in the central and the eastern equatorial Pacific. Regarding the rainfall asymmetry, the easterly wind anomalies during the cold phase were much weaker than the westerly wind anomalies during the warm phase over the central Pacific. In the simulations, the strong rainfall anomalies generated by the GAMIL2-related models were concentrated in the western and the central Pacific, whereas those from the CAM4-related models showed well-defined double bands and extended to the eastern Pacific, suggesting that the shapes of the precipitation extensions were determined mainly by the atmospheric components. Further, the precipitation anomalies simulated by CESM-g2 during the warm phase were slightly larger than those that developed during the cold phase, and the wind stress anomalies exhibited a similar contrast. However, in FGOALS-g2, the asymmetry of the precipitation (wind stress) anomalies between the warm and the cold phases was opposite to that in the observations, which was consistent with the negative SST skewness in its simulations. These results indicated that the asymmetry seen in precipitation (wind stress) in the two GAMIL2 models was also affected by the oceanic component, especially during the cold phase. CESM showed much stronger precipitation (wind stress) anomalies in the warm phase than the cold phase, and the precipitation (wind stress) asymmetry was more realistic (although there was an obvious double rain band in both the warm and the cold phase), which was consistent with the positive skewness of its SST anomalies. The precipitation anomalies in the FGOALS-c4 simulations shifted too far to the west during both the warm and the cold phases, and the positive residual was weak, especially in the eastern Pacific. In the two CAM4 models, the oceanic component affected the precipitation (wind stress) anomalies more obviously, showing in the shape of the westward extensions and in the strength during both phases. In addition, as the total precipitation was composed of convective and stratiform precipitation, to distinguish which kind of precipitation was connected with the SST asymmetry, the convective precipitation anomalies and the stratiform precipitation anomalies are shown in Figures 5 and 6, respectively. It was found that the total precipitation asymmetries were mainly contributed by the convective precipitation in terms of spatial distribution and magnitude. Hence, we concluded that the biases of the SST asymmetries were associated with those of convective precipitation and wind stress asymmetries, which were determined by both atmospheric and oceanic components. 
(a) Warm phase
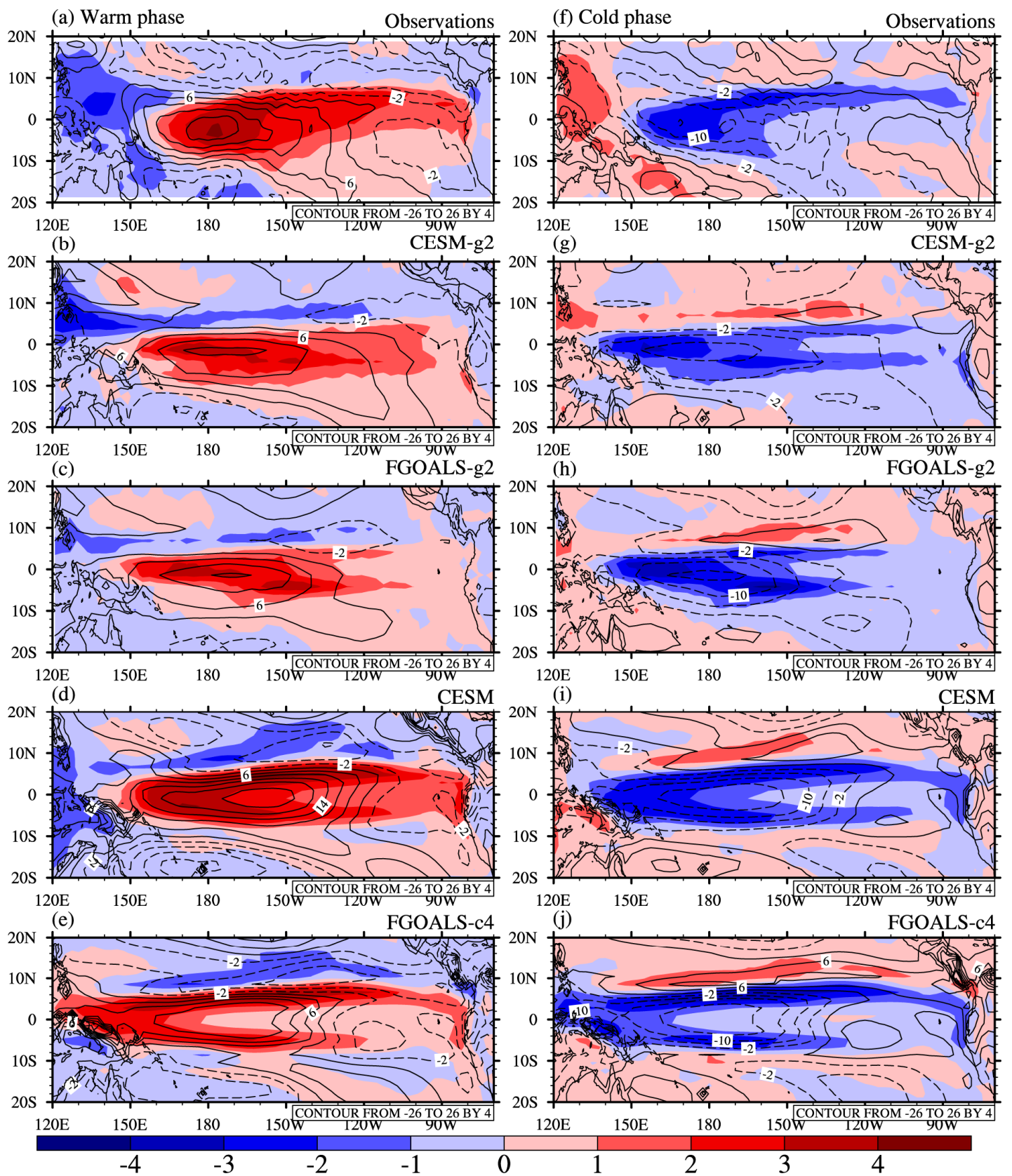

Figure 4. Spatial patterns of averaged composite anomalies of the warm phase (Left) and cold phase (Right) for precipitation (shaded; unit: $\mathrm{mm} /$ day) and zonal wind stress (contours; unit: $10^{-3} \mathrm{~N} / \mathrm{m}^{2}$ ) from $(\mathbf{a}, \mathbf{f})$ the observations and the four cross-coupled parent models: $(\mathbf{b}, \mathbf{g})$ CESM-g2, (c,h) FGOALS-g2, $(\mathbf{d}, \mathbf{i})$ CESM, $(\mathbf{e}, \mathbf{j})$ FGOALS-c4. The validation data for precipitation are from the Global Precipitation Climatology Project (GPCP) (1979-2009) and for zonal wind stress from SODA 2.2.4 (1958-1999). 
(a)Warm phase(mm/day) CESM-g2 (e)Cold phase(mm/day)
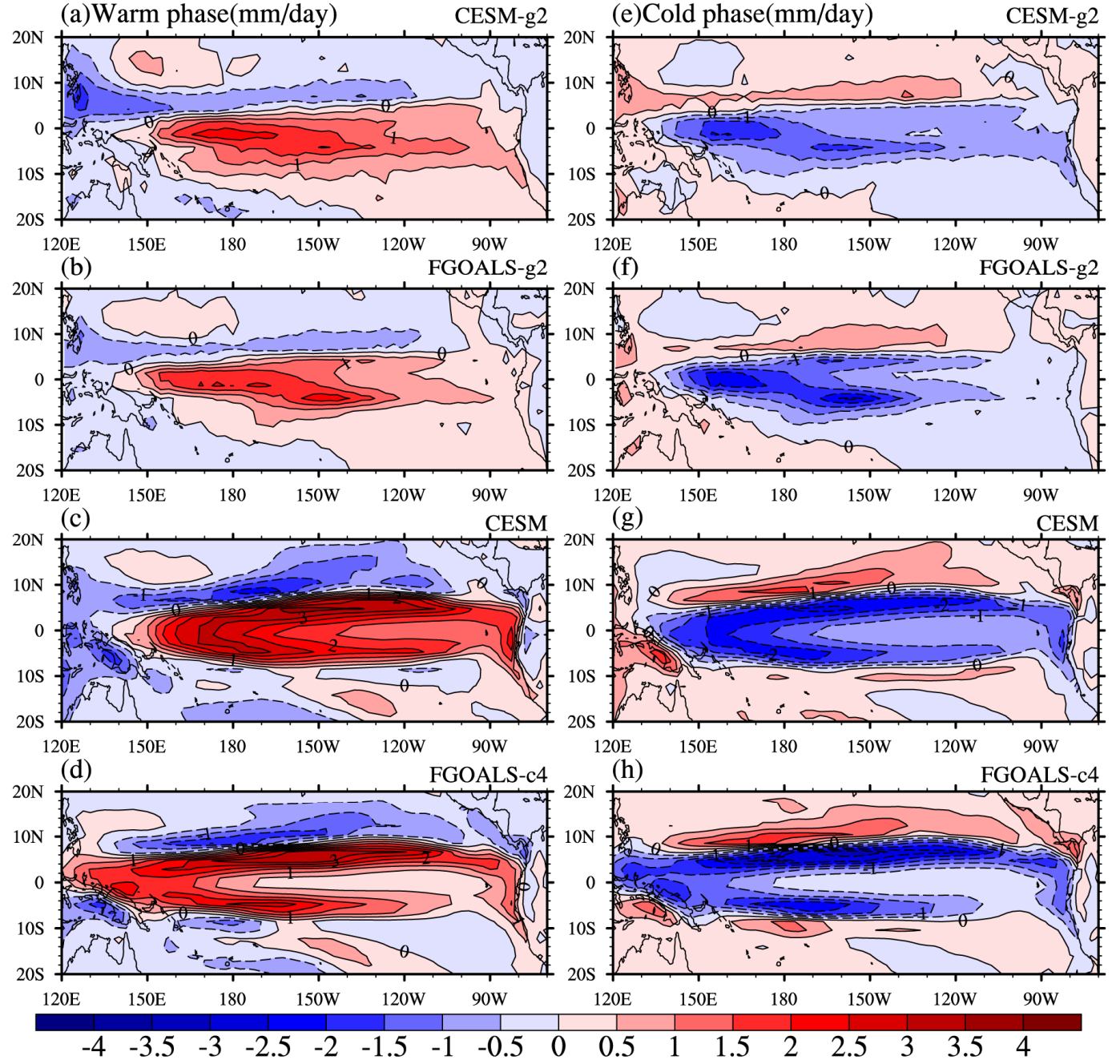

Figure 5. Spatial patterns of averaged composite anomalies of the warm phase (Left) and cold phase (Right) for convective precipitation from the four cross-coupled parent models: (a,e) CESM-g2, (b,f) FGOALS-g2, (c,g) CESM, (d,h) FGOALS-c4. 
(a)Warm phase(mm/day)

CESM-g2
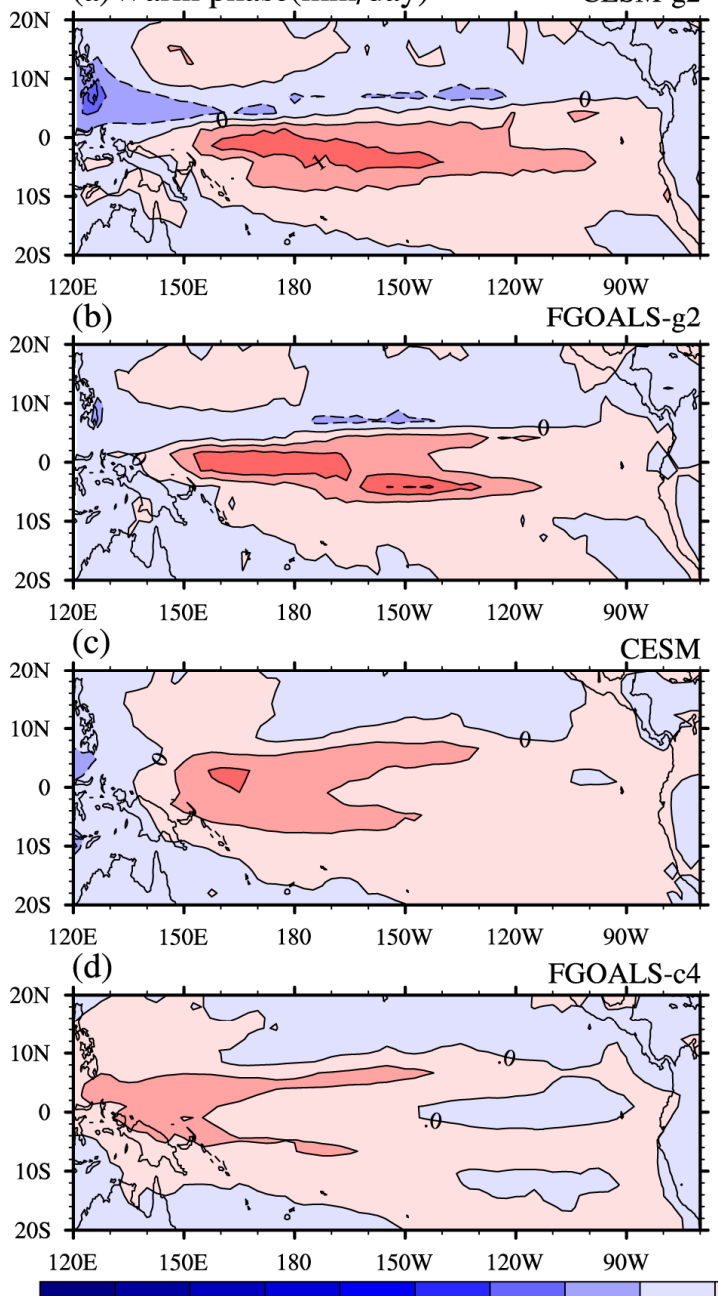

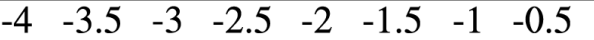
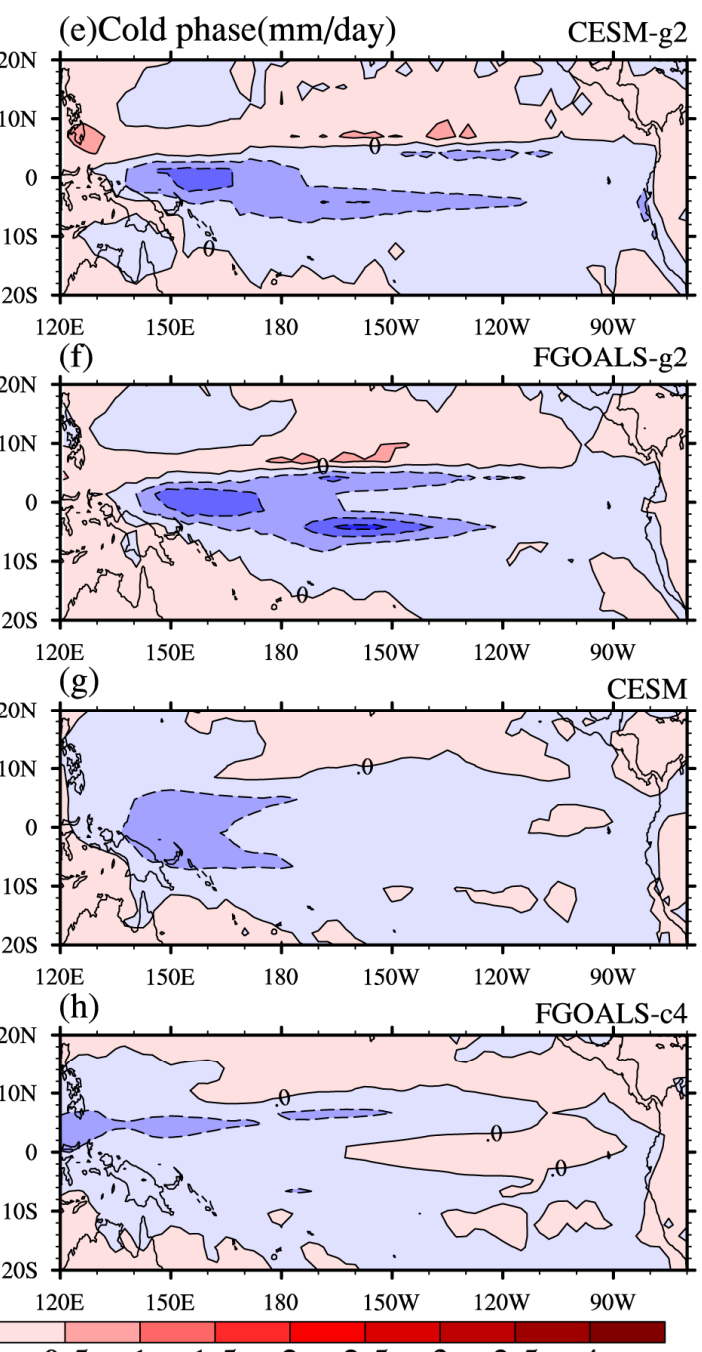

Figure 6. Spatial patterns of averaged composite anomalies of the warm phase (Left) and cold phase (Right) for stratiform precipitation from the four cross-coupled parent models: (a,e) CESM-g2, $(\mathbf{b}, \mathbf{f})$ FGOALS-g2, (c,g) CESM, (d,h) FGOALS-c4.

\section{Discussion and Conclusions}

To investigate the relative contribution of atmospheric and oceanic components to ENSO asymmetry, we analyzed ENSO using four "cross-coupled" models (CESM, FGOALS-g2, CESM-g2, and FGOALS-c4). Our results show that extreme ENSO events are determined mainly by the atmospheric components. These extreme events occurred mainly in the CAM4-related simulations (CESM and FGOALS-c4), whereas the GAMIL2-related models (CESM-g2 and FGOALS-g2) simulated the weaker ENSO events. Moreover, the stronger SST anomalies during the warm phase did not lead to increased SST asymmetry, and only the CESM simulations generated asymmetry that was similar to the observations. The skewness of the four simulations during years 401-500 could be affected by both atmospheric and oceanic components, with the atmospheric component determining the strength of the SST anomalies and the oceanic component further affecting the strength of the negative SST anomalies in the cold phase under the same atmospheric component group.

In observations, the BJ index of an El Niño event was larger than that of a La Niña event, which contributed to the El Niño-La Niña SSTA asymmetries. However, in climate model simulations, the BJ index of CESM-g2 and FGOALS-g2 in two phases reached an agreement with the skewness, while that of CESM and FGOALS-c4 was not self-consistent with the corresponding El Niño-La Niña asymmetry. The BJ index did not necessarily explain the El Niño-La Niña SSTA asymmetries in climate 
model simulations. The SST asymmetries simulated by the four coupled models were consistent with the asymmetries seen in the precipitation and the wind stress. In the CESM simulations, the realistic SST asymmetry was associated with stronger precipitation and wind stress anomalies during the warm phase when compared with the cold phase. The biases of the SST asymmetries in the other three models were associated with those in precipitation and wind stress asymmetries. In addition, the precipitation asymmetries were mainly contributed by the convective precipitation in terms of spatial distribution and magnitude. The convective precipitation and the wind stress asymmetries were determined by both atmospheric and oceanic components.

The influence of the component on precipitation and zonal stress asymmetry should be traced to the special processes of atmospheric and oceanic components in a future study. In addition, as shown in Table 1, the skewness value in the four models varies along with the period of integration in the PI-control runs. There may be some additional differences under other experiment scenarios, e.g., the skewness value of FGOALS-g2 was $0.2-0.3$ in the historical simulation [11] but had a negative value in this study. Hence, the mechanisms that cause skewness diversity associated with the centurial modulation as well as that caused by different external forcings should be investigated in a future study.

Author Contributions: Conceptualization, L.L., B.W. and W.D.; methodology, L.L. and P.L.; software, Y.T. and P.L.; validation, L.L., B.W., P.L., W.D. and K.X.; formal analysis, Y.T.; investigation, Y.T.; resources, Y.T.; data curation, Y.T., P.L. and W.D.; writing—original draft preparation, Y.T.; writing—review and editing, L.L.; visualization, Y.T. and L.L.; supervision, L.L., B.W. and W.D.; project administration, L.L. and B.W.; funding acquisition, Y.T., L.L. and K.X.

Funding: This research was funded by the National Natural Science Foundation of China (Grant Nos. 41605061; 41622503), the National Basic Research Program of China (973 Program, Grant No. 2015CB954102); the China Postdoctoral Science Foundation (Grant No. 1191005829), the National Key Research Project (Grant No. 2016YFB0200805), and the National Key Basic Research Program of China (Grant No. 2015CB954101).

Conflicts of Interest: The authors declare no conflict of interest.

\section{References}

1. Choi, K.Y.; Vecchi, G.A.; Wittenberg, A.T. ENSO transition, duration, and amplitude asymmetries: Role of the nonlinear wind stress coupling in a conceptual model. J. Clim. 2013, 26, 9462-9476. [CrossRef]

2. Rodgers, K.B.; Friederichs, P.; Latif, M. Tropical pacific decadal variability and its relation to decadal modulations of ENSO. J. Clim. 2004, 17, 3761-3774. [CrossRef]

3. Schopf, P.S.; Burgman, R.J. A simple mechanism for ENSO residuals and asymmetry. J. Clim. 2006, 19, 3167-3179. [CrossRef]

4. Dommenget, D.; Bayr, T.; Frauen, C. Analysis of the non-linearity in the pattern and time evolution of El Niño southern oscillation. Clim. Dyn. 2013, 40, 2825-2847. [CrossRef]

5. An, S.; Jin, F.F. Nonlinearity and asymmetry of ENSO. J. Clim. 2004, 17, 2399-2412. [CrossRef]

6. Su, J.; Zhang, R.; Li, T.; Rong, X.; Kug, J.S.; Hong, C.C. Causes of the El Niño and La Niña amplitude asymmetry in the equatorial eastern Pacific. J. Clim. 2010, 23, 605-617. [CrossRef]

7. Graham, N.E.; Barnett, T.P. Sea surface temperature, surface wind divergence, and convection over tropical oceans. Science 1987, 238, 657-659. [CrossRef]

8. Hoerling, M.P.; Kumar, A.; Zhong, M. El Niño, La Niña, and the nonlinearity of their teleconnections. J. Clim. 1997, 10, 1769-1786. [CrossRef]

9. Kang, I.S.; Kug, J.S. El Niño and La Niña sea surface temperature anomalies: Asymmetry characteristics associated with their wind stress anomalies. J. Geophys. Res. 2002, 107(D19), 4372. [CrossRef]

10. Zhang, T.; Sun, D.Z.; Neale, R.; Rasch, P.J. An evaluation of ENSO asymmetry in the community climate system models: A view from the subsurface. J. Clim. 2009, 22, 5933-5961. [CrossRef]

11. Zhang, T.; Sun, D.Z. ENSO asymmetry in CMIP5 models. J. Clim. 2014, 27, 4070-4093. [CrossRef]

12. Ham, Y.G. A reduction in the asymmetry of ENSO amplitude due to global warming: The role of atmospheric feedback. Geophys. Res. Lett. 2017, 44, 8576-8584. [CrossRef]

13. Tang, Y.; Li, L.; Dong, W.; Wang, B. Tracing the source of ENSO simulation differences to the atmospheric component of two CGCMs. Atmos. Sci. Let. 2016, 17, 155-161. [CrossRef] 
14. Tang, Y.; Li, L.; Wang, B.; Lin, P.; Chen, L.; Xie, F.; Dong, W.; Xia, K. The dominant role of the atmospheric component of coupled models in ENSO amplitude simulations. Clim. Dyn. 2019, 52, 4833-4847. [CrossRef]

15. Neale, R.B.; Richter, J.; Park, S.; Lauritzen, P.H.; Vavrus, S.J.; Rasch, P.J.; Zhang, M. The mean climate of the community atmosphere model (CAM4) in forced SST and fully coupled experiments. J. Clim. 2013, 26, 5150-5168. [CrossRef]

16. Smith, R.D.; Jones, P.; Briegleb, B.; Bryan, F.; Danabasoglu, G.; Dennis, J.; Dukowicz, J.; Eden, C.; Fox-Kemper, B.; Gent, P.; et al. The Parallel Ocean Program (POP) Reference Manual; Technical Report for Los Alamos National Laboratory LAUR-10-01853; Los Alamos National Laboratory: Los Alamos, NM, USA, 2010; p. 140.

17. Wang, B.; Wan, H.; Ji, Z.Z.; Zhang, X.; Yu, R.C.; Yu, Y.Q.; Liu, H.T. Design of a new dynamical core for global atmospheric models based on some efficient numerical methods. Sci. China Math. 2004, 47, 4-21. [CrossRef]

18. Li, L.J.; Wang, B.; Dong, L.; Liu, L.; Shen, S.; Hu, N.; Sun, W.Q.; Wang, Y.; Huang, W.Y.; Shi, X.J.; et al. Evaluation of gridpoint atmospheric model of IAP LASG Version 2 (GAMIL2). Adv. Atmos. Sci. 2013, 30, 855-867. [CrossRef]

19. Liu, H.L.; Lin, P.F.; Yu, Y.Q.; Zhang, X.H. The baseline evaluation of LASG/IAP climate system ocean model (LICOM) version 2.0. Acta Meteorol. Sin. 2012, 26, 318-329. [CrossRef]

20. Wu, F.; Liu, H.; Li, W.; Zhang, X. Effect of adjusting vertical resolution on the eastern equatorial Pacific cold tongue. Acta Meteorol. Sin. 2005, 24, 1-12.

21. Tang, Y.; Li, L.; Dong, W.; Wang, B. Reducing the climate shift in a new coupled model. Sci Bull. 2016, 61, 488-494. [CrossRef]

22. Lin, P.F.; Liu, H.L.; Xue, W.; Li, H.M.; Jiang, J.R.; Song, M.R.; Song, Y.; Wang, F.C.; Zhang, M.H. A coupled experiment with LICOM2 as the ocean component of CESM1. J. Meteor. Res. 2016, 30, 76-92. [CrossRef]

23. Hurrell, J.W.; Hack, J.J.; Shea, D.; Caron, J.M.; Rosinski, J. A new sea surface temperature and sea ice boundary dataset for the community atmosphere model. J. Clim. 2008, 21, 5145-5153. [CrossRef]

24. Uppala, S.M.; Kållberg, P.W.; Simmons, A.J.; Andrae, U.; Bechtold, V.D.C.; Fiorino, M.; Gibson, J.K.; Haseler, J.; Angeles, H.C.; Kelly, G.A.; et al. The ERA-40 re-analysis. Q. J. Roy. Meteor. Soc. 2005, 131, 2961-3012. [CrossRef]

25. Adler, R.F.; Huffman, G.J.; Chang, A.; Ferraro, R.; Xie, P.P.; Janowiak, J.; Rudolf, B.; Schneider, U.; Curtis, S.; Bolvin, D.; et al. The version-2 global precipitation climatology project (GPCP) monthly precipitation analysis (1979-Present). J. Hydrometeor. 2003, 4, 1147-1167. [CrossRef]

26. Carton, J.A.; Giese, B.S. A reanalysis of ocean climate using simple ocean data assimilation. Mon. Weather Rev. 2008, 136, 2999-3017. [CrossRef]

27. Giese, B.S.; Ray, S. El Niño variability in simple ocean data assimilation (SODA), 1871-2008. J. Geophys. Res. 2011, 116, C02024. [CrossRef]

28. Kim, S.T.; Jin, F.F. An ENSO stability analysis. Part I: Results from a hybrid coupled model. Clim. Dyn. 2011, 36, 1593-1607. [CrossRef]

29. Jin, F.F.; Kim, S.T.; Bejarano, L. A coupled stability index for ENSO. Geophys. Res. Lett. 2006, 33, L23708. [CrossRef]

30. Chen, L.; Yu, Y.; Zheng, W. Improved ENSO simulation from climate system model FGOALS-g1.0 to FGOALS-g2. Clim. Dyn. 2016, 47, 2617-2634. [CrossRef]

31. Im, S.H.; An, S.I.; Kim, S.T.; Jin, F.F. Feedback processes responsible for El Niño-La Niña amplitude asymmetry. Geophys. Res. Lett. 2015, 42, 5556-5563. [CrossRef]

32. Chen, L.; Wang, L.; Li, T.; Sun, D.Z. Contrasting cloud radiative feedbacks during warm pool and cold tongue El Niños. SOLA 2018, 14, 126-131. [CrossRef]

33. Chen, L.; Sun, D.Z.; Wang, L.; Li, T. A further study on the simulation of cloud-radiative feedbacks in the ENSO cycle in the tropical pacific with a focus on the asymmetry. Asia-Pacific. J. Atmos. Sci. 2019, 55, 303-316. [CrossRef]

34. Ham, Y.G.; Kug, J.S.; Kim, D.; Kim, Y.H.; Kim, D.H. What controls phase-locking of ENSO to boreal winter in coupled GCMs? Clim. Dyn. 2013, 40, 1551-1568. [CrossRef]

(C) 2019 by the authors. Licensee MDPI, Basel, Switzerland. This article is an open access article distributed under the terms and conditions of the Creative Commons Attribution (CC BY) license (http://creativecommons.org/licenses/by/4.0/). 